\title{
BMJ Global Health Towards the real-time inclusion of sex- and age-disaggregated data in pandemic responses
}

\author{
Shirin Heidari (D) , , ${ }^{1,2}$ Claudia Ahumada, ${ }^{2}$ Ziyoda Kurbanova (D) , ${ }^{2}$ GENDRO Gender, \\ Evidence and Health Network
}

To cite: Heidari S, Ahumada C, Kurbanova Z, et al. Towards the real-time inclusion of sex- and age-disaggregated data in pandemic responses. BMJ Global Health 2020;5:e003848. doi:10.1136/ bmjgh-2020-003848

Received 31 August 2020 Accepted 31 August 2020

Check for updates

(c) Author(s) (or their employer(s)) 2020. Re-use permitted under CC BY-NC. No commercial re-use. See rights and permissions. Published by BMJ.

${ }^{1}$ Global Health Centre, Graduate Institute of International and Development Studies, Geneva, Switzerland

${ }^{2}$ GENDRO, Geneva, Switzerland

Correspondence to

Dr Shirin Heidari;

s.heidari@gendro.org
Early data provide evidence that sex and gender are important factors that intersect with each other and with other social determinants to influence susceptibility and vulnerability to COVID-19. Sex and gender, along with other key variables such as age, can influence disease progression, outcome and access to services, as well as social, psychological and economic impacts. Similar patterns have been observed in other global outbreaks (eg, HIV, Ebola, Zika) where a complex interplay of gender and other dimensions of vulnerability have resulted in disparate health outcomes. Through these epidemics, the world has witnessed the implications of neglecting gender dynamics; ${ }^{1}$ from heightened risk of infection, increased mortality and greater susceptibility to other health problems, social vulnerability and economic insecurity. These experiences, together with pressure from civil society, have over the years prompted the adoption of a number of political commitments to gender-sensitive public health responses, including the need to produce gender-sensitive evidence. While these commitments are welcome, whether they will be translated into action remains a matter of discretion and political will.

\section{COVID-19 REQUIRES A GENDER-SENSITIVE RESPONSE}

The emergence and spread of COVID-19 have reinvigorated the conversation on the importance of fulfilling commitments to genderresponsive approaches to public health, ensuring that gender is part of pandemic responses and leadership considerations. WHO's Director-General, Dr Tedros Adhanom Ghebreyesus, has affirmed that 'tackling (the) pandemic requires a gender-responsive, equityoriented and human rights-based approach ${ }^{2}$ while underlining WHO's commitment 'to using a gender lens to continuously evaluate and improve our response efforts'.

Despite experience from other global health crises and existing commitments, we have failed to gather and share adequate gender-sensitive evidence to guide COVID-19 responses. While data and research on COVID-19 are being produced at unprecedented speed, reporting of the data disaggregated by sex-let alone by sex and age-remains rare. ${ }^{4}$ Growing numbers of countries have begun to report their confirmed cases and deaths by sex and sometimes by sex and age. ${ }^{5}$ However, according to WHO, as of 22 September 2020, only $27 \%$ of 31038914 confirmed cases of COVID-19 had been reported to the Organization with data on sex and age. ${ }^{67}$

While the reporting form for confirmed COVID-19 cases captures ${ }^{8}$ this information, because relatively few countries report the case data to the WHO, these data do not provide the full picture. Because sex-disaggregated data are scant across age groups on comorbidities or other risk factors, as well as on testing, symptoms, hospitalisation and intensive care (including criteria), discharge and recovery—or even excess mortality ${ }^{9}$-we are left in the dark about how the pandemic affects women and men across different age groups in different countries. The problematic lack of standard age disaggregation is another challenge that hinders meaningful comparison of infection and mortality rates among women and men of different age groups, particularly for older and younger groups. Data that go beyond sex to also look at the broader spectrum of gender-related differences are even scarcer. Similarly, the clinical trials of new medicines and vaccine candidates that have been initiated at an unparalleled rate fail to share information about the gender balance of trials or how trials are designed to capture sex differences and gender dimensions. ${ }^{1011}$ 


\section{SEX- AND AGE-DISAGGREGATED DATA ARE A PREREQUISITE FOR AN EFFECTIVE RESPONSE}

The scarcity of disaggregated data is not new. In the past, in the context of diseases with a greater burden in low-income countries, such as the HIV epidemic, the lack of resources and capacity, coupled with poor health information systems, has been invoked for not collecting or reporting sexdisaggregated data. However, countries at the epicentre of the COVID-19 pandemic are mostly high-income countries with advanced and robust health information systems, which undoubtedly collect data on sex and age in electronic medical records yet fail to analyse or report the data in terms of gender.

As affirmed by WHO's Director-General in opening the Seventy-third World Health Assembly (WHA) in May 2020, 'The world does not lack the tools, the science or the resources to make it safer from pandemics. What it has lacked is the sustained commitment to use the tools, the science and the resources it has. ${ }^{12}$ In addition, most if not all affected countries are WHO Member States which in 2007 adopted the resolution WHA60.25 ${ }^{13}$ whereby they committed to collect and analyse sex-disaggregated data, while undertaking research to understand factors that contribute to gender disparities in order to use the evidence to inform policies and programmes.

Lack of continuous monitoring of sex- and agedisaggregated data limits the effectiveness of pandemic responses. Early data from China and other preliminary analyses indicate that men are at greater risk of death from COVID-19 than women are, as explained by higher prevalence of smoking and comorbidities among men and a stronger biological immune response in women. ${ }^{14}$ While this continues to hold true in many countries, the paucity of sex- and age-disaggregated data and the observed variability across countries warn against early assumptions.

Mounting data reveal notable geographical variability that merits further investigation in order to understand the extent of, and reasons for, gender differences across age groups and locations. In the Republic of Korea, a country with higher detection rates, more women than men were reported as infected with COVID-19 (54.72\% of women vs $45.28 \%$ of men). A similar picture can be observed in Spain with recent data showing more women being infected (51.2\% of women vs $48.5 \%$ of men).$^{15}$ In Italy, a similar trend can be observed ( $53 \%$ of women vs $47 \%$ of men) with some variations across age group. ${ }^{16}$

Despite variations in the male-to-female infection ratio, data continue to suggest higher case fatality rates ${ }^{\mathrm{i}}$ among men compared with women in most of the countries and in most age groups, with a few exceptions. However, the size difference varies greatly. In the Islamic Republic of Iran, the

\footnotetext{
${ }^{\mathrm{i}}$ The case fatality rate is the number of deaths divided by the number of confirmed cases. Case fatality rates are very uncertain as they vary significantly both between countries (as a result of the extent of testing) and over time (as a result of how many of confirmed cases will die or recover). There is also a selection bias in case fatality rates because severe cases are more likely to be tested.
}

difference in reported death rates among women and men with confirmed cases seem to be much smaller (12\% higher in men than in women) than that in Spain (73\% higher in men than in women) $)^{\text {ii }}$. Finland and Pakistan report a slightly higher case fatality rate for women compared with men. ${ }^{17}$ These variances are probably due to a combination of factors, including transmission patterns, immunological differences, variability in prevalence of comorbidities or other risk factors (such as smoking and exposure to higher levels of air or household pollution), frequency of exposure and the viral load-but also the rate of and access to testing and case detection.

Infection and fatality rates across genders and age groups may also change over time as the pandemic evolves. Is it possible that there has been a time lag in infections in women, shaped by patterns of social mobility, international travel and transmission patterns? If this is the case, as is indicated by the preliminary data from Spain (from $78 \%$ of men vs $22 \%$ of women infected by 28 February, ${ }^{18}$ the rates of infection had changed to $48.5 \%$ vs $51.2 \%$, respectively, by 20 August $^{15}$ we may expect that the gender differences in infection and death rates may possibly change as the pandemic matures. This is probable given the increase in infections among healthcare workers, most of whom are younger women.

In Italy, by mid-March, approximately $20 \%$ of healthcare workers were infected with the virus. Data from Italy, Germany, Spain and the USA show that women account for $60 \%-70 \%$ of confirmed cases among healthcare workers. Evidence from Spain also shows that women are more exposed through contact with COVID-19-infected persons or by visiting health centres, resulting from their excessive caregiving responsibilities or as a result of being healthcare workers. Since the start of the outbreak in Spain, 35548 cases of COVID-19 were confirmed in health workers by 7 May, of which $76 \%$ were women with median age of 46 years. ${ }^{19}$ The heightened vulnerability of women on the frontlines has been underscored by reports of gender blindness and bias in health systems-such as ill-fitting personal protective equipment designed for the male anatomy. ${ }^{20}$

We also have insufficient public data to rule out potential differences in symptoms and in the presentation of disease in women and men which may result in potential underdiagnosis or misdiagnosis. Data from other disease areas, such as cardiovascular diseases, have revealed that women and men may display differential symptoms that lead potentially to missed diagnosis or missed opportunities to seek care. Anecdotal data indicate that certain COVID-19 symptoms may be more common among men or, indeed, among women (eg, sore throat, vomiting and diarrhoea could be more common in women, whereas fever, breathing problems and pneumonia could be more frequent in men, as reported by Spain on 13 and 20 March 2020). While the data are too limited to draw any meaningful conclusions, there is a need for better

\footnotetext{
${ }^{\mathrm{ii}}$ See: Global Health 50/50. COVID-19 Sex-disaggregated Data Tracker. https://globalhealth5050.org/COVID-19/sex-disaggregated-data-tracker/, according to data provided on 21 May 2020 .
} 
gender analysis in order to have a more accurate understanding of clinical features, severity of disease, risk factors for infection and transmission patterns among women and men at different ages and in different settings.

\section{LESSONS FROM THE PAST OUTBREAKS}

In examining emerging studies on COVID-19, it is remarkable that gendered dimensions are being taken into consideration in only a subset of the studies; data disaggregated by sex and age continue to be poorly available. A review of published research on Ebola and Zika revealed that less than $1 \%$ of studies considered the gender implications of these outbreaks. ${ }^{21}$ Studies of gender blindness in past research have exposed negative implications such as gender biases in healthcare, misdiagnosis, poorer treatment and worse outcomes, mainly for women but also for men. Hence, in the context of limited testing capacities and overburdened health systems, gender bias based on premature assumptions can influence decisions about testing, admission and treatment. ${ }^{22}$ We need to ensure that these historical biases are not reinforced in a time and age when we have better knowledge of the impacts of gender dynamics on health and when we can leverage digitalised health information systems.

A more complete picture of the differential patterns of transmission, presentation and outcome of COVID-19 disease by gender and age, among other elements, can result in tailored measures, innovative interventions or adjustments of the responses resulting in increased effectiveness. Standardisation of age grouping for health statistics will also be critical to ensure consistency in reporting. The use of more granular data in analytical models and health impact assessment tools can enhance the accuracy and reliability of predictions and estimates and can indicate how changes to policies and practices can improve outcomes. Understanding disparities and inequities can also have a secondary effect in that it forces us to face pervasive societal questions as to why certain genders or populations are at greater risk. While we recognise that reporting and analysis of sex- and agedisaggregated data are by no means sufficient to provide a comprehensive picture of the complex intersectional gender dynamics in the pandemic, it is a prerequisite for starting to identify potential gender-related disparities and for guiding future research.

\section{CALL TO ACTION}

As we embark on this challenging and enduring public health emergency, we are reminded to learn from past lessons and to deliver on commitments to ensure a gender-sensitive response to pandemics-a response that is informed by evidence and rooted in human rights principles. Countries have an obligation to share comprehensive and accurate data disaggregated by sex and age as a minimum (as requested in WHO weekly aggregate reporting ${ }^{8}$ ) and to apply intersectional gender-based analyses to strive continuously for better understanding of the evolving pandemic. ${ }^{6}$

The responsibility to collect and analyse age and gender dimensions does not fall only on national public health agencies. Researchers around the world have a moral and scientific responsibility to integrate sex and gender dimensions into their research from the outset. Journal editorsimportant gatekeepers of science and evidence, many of whom have pledged to improve the reporting of sex and gender in peer-reviewed journals-are called to act on their commitments and request authors to provide all data disaggregated by sex and age at a minimum. ${ }^{23}$ Research funding agencies-such as the National Institutes of Health, the Canadian Institutes of Health Research and the European Commission-should reinforce their gender policies for expedited funding for research on COVID-19. Only then shall we be able to have a comprehensive understanding of the current pandemic and a response which is meaningful to people of all genders and ages.

Twitter Shirin Heidari @heidari_s, Claudia Ahumada @ClaudiaAhumadaG, Ziyoda Kurbanova @ziyodaadoyiz and GENDRO Gender, Evidence and Health Network @GendroOrg

Acknowledgements We greatly appreciate the comments and contributions of several colleagues at WHO on this commentary. These are: Adama Diop, Boris Pavlin, Evelyn Boy-Mena, Gerardo Zamora, Heather Monnet, Mariam Otmani del Barrio, Michela Manna, Michelle Mclsaac and Theresa Diaz.The open access costs for this publication was made possible through the generous support provided by discretionary research funds from Dr David Beran, Researcher and Lecturer at the Division of Tropical and Humanitarian Medicine, the Geneva University Hospitals and University of Geneva (UNIGE). We extend our gratitude to Dr David Beran

Collaborators GENDRO Gender, Evidence and Health Network: Aaban Butt, GAVl; Abha Saxena, Independent; Alexandra Calmy, Geneva University Hospital; Ana Gurau, University of Geneva; Bernard Kadasia, GENDRO; Claire Sommerville, Graduate Institute of International and Development Studies; David Beran, University of Geneva; Dina Handan, Boston University; Ellen Rosskam, Webster University; Gaurav Garg, GAVl; Heather Doyle, The Global Fund; Hilary Homans, Independent; Jennifer Hasselgård, Graduate Institute of International and Development Studies; Kasia Daghigh, International AIDS Society; Kwaku Adomako, University of Lausanne; Maria Halkias, GENDRO; Mariama Tavares, Graduate Institute of International and Development Studies; Marina Smelyanskaya, Stop TB Partnership; Maya Malarski, GAVI; Najia Musolino, International Society of Geriatric Oncology; Olivia Mettler, GENDRO; Sahar Hejazi, UNICEF; Sara Meg Davis, Graduate Institute of International and Development Studies; Sarah Simpson, Equinet; Simona Isler, Swiss National Science Foundation; Victoria Boydell, Graduate Institute of International and Development Studies.

Contributors SH wrote the initial draft of the manuscript, CA and ZK contributed to subsequent revisions. All other authors provided critical feedback to the manuscript.

Funding The authors have not declared a specific grant for this research from any funding agency in the public, commercial or not-for-profit sectors.

Disclaimer The views and opinions expressed in this commentary are those of the authors and do not necessarily reflect the views, decisions, or policies of their respective organizations.

Competing interests None declared.

Patient and public involvement Patients and/or the public were not involved in the design, or conduct, or reporting, or dissemination plans of this research.

Patient consent for publication Not required.

Provenance and peer review Not commissioned; internally peer reviewed.

Data availability statement No preliminary data was collected, and all data are from public sources.

Open access This is an open access article distributed in accordance with the Creative Commons Attribution Non Commercial (CC BY-NC 4.0) license, which permits others to distribute, remix, adapt, build upon this work non-commercially, and license their derivative works on different terms, provided the original work is properly cited, appropriate credit is given, any changes made indicated, and the use is non-commercial. See: http://creativecommons.org/licenses/by-nc/4.0/. 
Author note Visit https://www.gendro.org/ to endorse GENDRO's call for urgent action: a renewed commitment to gender-responsive research for health equity and human rights in the context of the COVID-19 pandemic.

\section{ORCID iDs}

Shirin Heidari http://orcid.org/0000-0002-6837-491X

Ziyoda Kurbanova http://orcid.org/0000-0002-4792-875X

\section{REFERENCES}

1 Smith J. Overcoming the 'tyranny of the urgent': integrating gender into disease outbreak preparedness and response. Gend Dev 2019;27:355-69.

2 World Health Organization. Live from WHO Headquarters COVID-19 daily press briefing, 2020. Available: https://youtu.be/ 1V3AonONQ7g?t=979 [Accessed 20 September 2020].

3 International Gender Champions. COVID-19: what does this mean for gender? 2020. Available: https://genderchampions.com/news/ covid-19-what-does-this-mean-for-gender

4 European Centre for Disease Prevention and Control. COVID-19 situation update worldwide, 2020. Available: https://www.ecdc. europa.eu/en/geographical-distribution-2019-ncov-cases

5 Global health 50/50. Available: https://globalhealth5050.org

6 World Health Organization. Gender and COVID-19: advocacy brief, 2020. Available: https://apps.who.int/iris/handle/10665/332080

7 World Health Organization. Who coronavirus disease (COVID-19) Dashboard. Available: https://covid19.who.int [Accessed 20 September 2020].

8 World Health Organization. Global surveillance for COVID-19 caused by human infection with COVID-19 virus: interim guidance, 2020. Available: https://www.who.int/docs/default-source/coronaviruse/ global-surveillance-for-covid-v-19-final200321-rev.pdf [Accessed 20 September 2020].

9 Krieger N, Chen JT, Waterman PD. Excess mortality in men and women in Massachusetts during the COVID-19 pandemic. Lancet 2020;395:S0140673620312344.

10 Global Coronavirus COVID-19 Clinical Trial Tracker. Available: https://www.covid-trials.org

11 Bischof E, Oertelt-Prigione S, Morgan R, et al. Towards precision medicine: inclusion of sex and gender aspects in COVID-19 clinical Studies-Acting now before it is too Late-A joint call for action. Int J Environ Res Public Health 2020;17:3715.

12 WHO Director-General's opening remarks at the World Health Assembly, 2020. Available: https://www.who.int/dg/speeches/detail/ who-director-general-s-opening-remarks-at-the-world-healthassembly
13 World Health Organization. Strategy for Integrating Gender Analysis and Actions into the Work of WHO, 2008. Available: https://apps. who.int/iris/bitstream/handle/10665/69857/WHO_FCH_GWH_08.1_ eng.pdf?sequence $=1$

14 Cai H. Sex difference and smoking predisposition in patients with COVID-19. Lancet Respir Med 2020;8:e20.

15 Red Nacional de Vigilancia Epidemiológica (RENAVE). Instituto de Salud Carlos III, 2020. Informe n40. Situación de COVID-19 en España a 20 de agosto de 2020. Available: https://www.isciii.es/ QueHacemos/Servicios/VigilanciaSaludPublicaRENAVE/Enfermed adesTransmisibles/Paginas/-COVID-19.-Informes-previos.aspx [Accessed 20 September 2020].

16 ISS Working Group for Translational Research COVID-19. Recommendations for the collection and analysis of data disaggregated by sex related to incidence, manifestations, response to therapies and outcomes in COVID-19 patients. Roma, Italy: Istituto Superiore di Sanit, 2020. https://www.iss.it/documents/ 20126/0/Rapporto+ISS+COVID-19+n.+18+gender+EN.pdf/ d476c8e4-73d2-7ff6-da81-6dbb26b4f8e8?t=1590136420616

17 COVID-19: emerging gender data and why it matters. Available: https://data.unwomen.org/resources/covid-19-emerging-genderdata-and-why-it-matters

18 Red Nacional de Vigilancia Epidemiológica (RENAVE). Instituto de Salud Carlos III, 2020. Informe sobre Los casos de COVID-19 confirmados en España. Informe COVID-19 no 3. 28 de febrero de 2020. Available: https://www.isciii.es/QueHacemos/Servicios/Vigi lanciaSaludPublicaRENAVE/EnfermedadesTransmisibles/Paginas/COVID-19.-Informes-previos.aspx [Accessed 20 September 2020].

19 Red Nacional de Vigilancia Epidemiológica (RENAVE). Instituto de Salud Carlos III, 2020. Informe n²9. Situación de COVID-19 en España a 07 de Mayo de 2020. Available: https://www.isciii.es/ QueHacemos/Servicios/VigilanciaSaludPublicaRENAVE/Enfermed adesTransmisibles/Paginas/-COVID-19.-Informes-previos.aspx [Accessed 20 September 2020].

20 Topping A. Sexism on the Covid-19 frontline: 'PPE is made for a $6 \mathrm{ft}$ 3in rugby player', 2020. Available: https://www.theguardian.com/ world/2020/apr/24/sexism-on-the-covid-19-frontline-ppe-is-madefor-a-6ft-3in-rugby-player

21 Davies SE, Bennett B. A gendered human rights analysis of Ebola and Zika: locating gender in global health emergencies. Int Aff 2016;92:1041-60.

22 Laville S. London woman dies of suspected Covid-19 after being told she was 'not priority, 2020. Available: https://www.theguardian. $\mathrm{com} /$ world/2020/mar/25/london-woman-36-dies-of-suspectedcovid-19-after-being-told-she-is-not-priority?CMP=Share_iOSApp_ Other

23 Heidari S, Babor TF, De Castro P, et al. Sex and gender equity in research: rationale for the SAGER guidelines and recommended use. Res Integr Peer Rev 2016;1:2. 